\title{
(2) OPEN ACCESS \\ Continuous acellular material accumulation in the anterior chamber associated with corneal endothelial changes
}

\author{
Jun Shimazaki, ${ }^{1,2}$ Seika Den, ${ }^{1,3}$ Yoshiyuki Satake, ${ }^{1}$ Kazunari Higa ${ }^{2}$
}

\begin{abstract}
'Ophthalmology, Tokyo Dental College Ichikawa General Hospital, Ichikawa, Chiba, Japan ${ }^{2}$ Cornea Center Eye Bank, Tokyo Dental College Ichikawa General Hospital, Ichikawa, Chiba, Japan ${ }^{3}$ Ophthalmology, Jikei University School of Medicine, Minato-ku, Tokyo, Japan
\end{abstract}

\section{Correspondence to}

Professor Jun Shimazaki; jun@eyebank.or.jp

Accepted 16 October 2020
Check for updates

(c) BMJ Publishing Group Limited 2020. Re-use permitted under CC BY-NC. No commercial re-use. See rights and permissions. Published by BMJ.

To cite: Shimazaki J, Den $S$, Satake Y, et al. BMJ Case Rep 2020;13:e237417. doi:10.1136/bcr-2020237417

\section{SUMMARY}

This case series included two healthy adults who showed continuous production of acellular materials in the anterior chamber without inflammation. The materials were membrane-like in case 1 and amorphous in case 2; they gradually changed shape and location over several years. During follow-up, there were no changes in vision, the iris or the chamber angle. Anterior segment optical coherence tomography confirmed the attachment of the membrane to the corneal endothelium. Specular microscopy showed normal endothelial counting with reversal of the normal light/dark patterns that occasionally returned to normal appearances. Although acellular materials were observed unilaterally in both cases, abnormal endothelial images were noted in both eyes of case 1. Histopathological examinations demonstrated the absence of cellular components with negative immunostaining for collagen IV, vimentin and $\alpha$-smooth muscle actin. Serial ophthalmic examinations and histopathological findings suggest that the production of acellular material was associated with alterations of the corneal endothelium.

\section{BACKGROUND}

The anterior chamber occasionally shows an inflammatory response in cases of uveitis or trauma. The human corneal endothelium is a non-proliferating tissue responsible for maintaining the cornea in a state of deturgescence. Although some corneal endothelial disorders (eg, endothelitis and immunological rejection following keratoplasty) may be associated with mild anterior chamber reaction, these disorders typically do not lead to the production of materials in the anterior chamber. Here, we describe two cases in which acellular materials were continuously produced in the anterior chamber, in association with morphological alterations of the corneal endothelium.

\section{CASE PRESENTATION \\ Case 1}

A 48-year-old male office worker complained of occasional mild blurred vision and injection in his right eye, which had been present for approximately 3 months; he was referred for detailed examinations. The patient had no history of ocular diseases, surgery, trauma, long-term exposure to heat or systemic diseases. On examination, the bestcorrected visual acuity (BCVA) was 20/20. Slit lamp examination revealed mobile transparent membranous materials in the anterior chamber of the right eye (figure 1A). Both corneas were clear without endothelial irregularities. Despite mild ciliary injection, there was no anterior chamber inflammation. The iris was normal, and the pupil was round and symmetric. The crystalline lens was clear without deposition of exfoliation materials (figure 1B). The intraocular pressure (IOP) was $10 \mathrm{~mm} \mathrm{Hg}$ in both eyes. Anterior segment optical coherence tomography (AS-OCT) (CASIA; Tomey, Nagoya, Japan) showed that the membrane was located posterior to the corneal endothelium (figure 1C). Additional AS-OCT (Cirrus; Carl Zeiss Medic, Tokyo, Japan) confirmed attachment to the endothelium (figure 1D). Specular microscopy showed normal endothelial cell counts (right eye, 2829/ $\mathrm{mm}^{2}$; left eye, $2865 / \mathrm{mm}^{2}$ ) with abnormal images composed of round dark areas present in each cell, showing reversal of the normal light/dark patterns in both eyes (figure 2A). The central corneal thickness was $536 \mu \mathrm{m}$ in the right eye. Gonioscopy showed that the angle was open without anterior synechiae. Confocal microscopy (HRT II Rostock Cornea Module; Heidelberg Engineering, Dossenheim, Germany) revealed a round hyporeflective structure in each cell (figure 1E). After discussion with the patient and acquisition of informed consent, extraction of membranous tissue was performed 1 month after initial presentation; this enabled elucidation of the cause of membrane production. Extraction was performed in the operating room via paracentesis using fine forceps. Histopathological examination revealed that the material was amorphous without cellular components (figure 1F); it was also negative for collagen IV, vimentin and $\alpha$-smooth muscle actin immunostaining.

Topical administration of fluorometholone $(0.1 \%$ Flumetholon; Santen Pharmaceutical, Osaka, Japan) four times per day was performed for 5 months. However, the patient experienced occasional mild hyperaemia without changes in visual function. The membranous materials reaccumulated within 2 weeks after surgical extraction. Over 3 years of follow-up, the membranous materials were continuously produced in multiple regions with different configurations. No changes in the iris or IOP were noted. There were no changes in subjective symptoms, and specular microscopy occasionally revealed an almost normal appearance in both eyes (figure 2B). However, specular microscopic changes were observed in all directions, in both eyes simultaneously (figure $3 \mathrm{~A}, \mathrm{~B}$ ). 

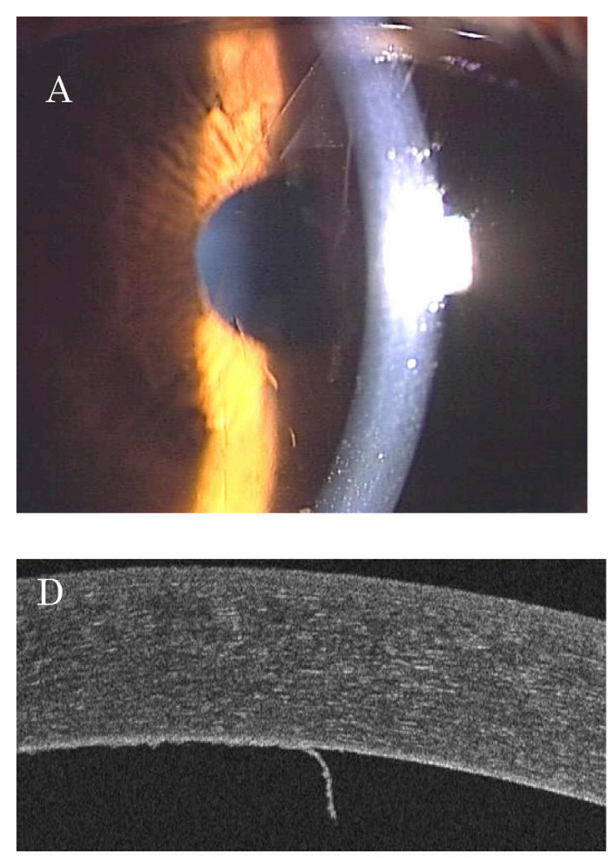
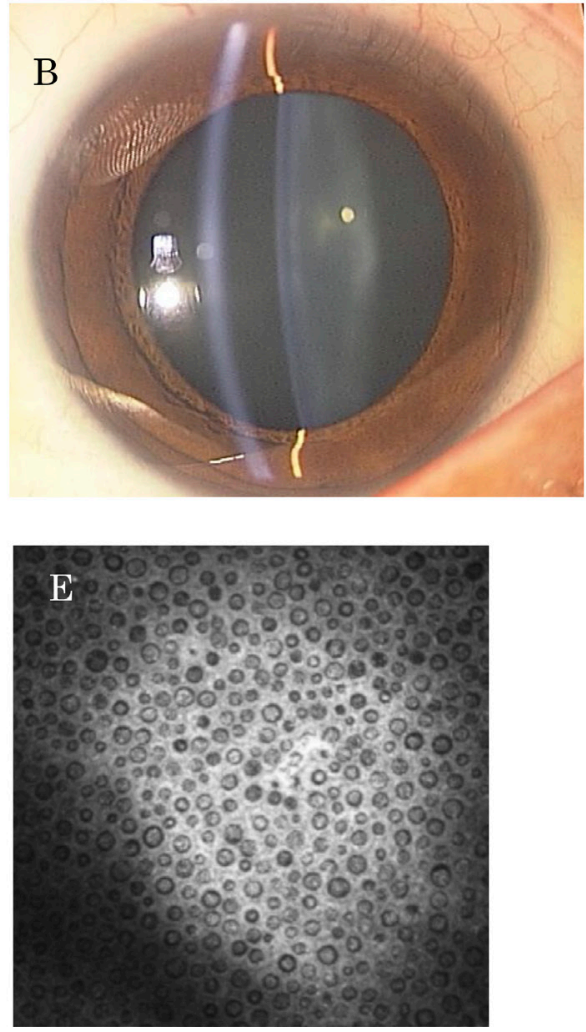
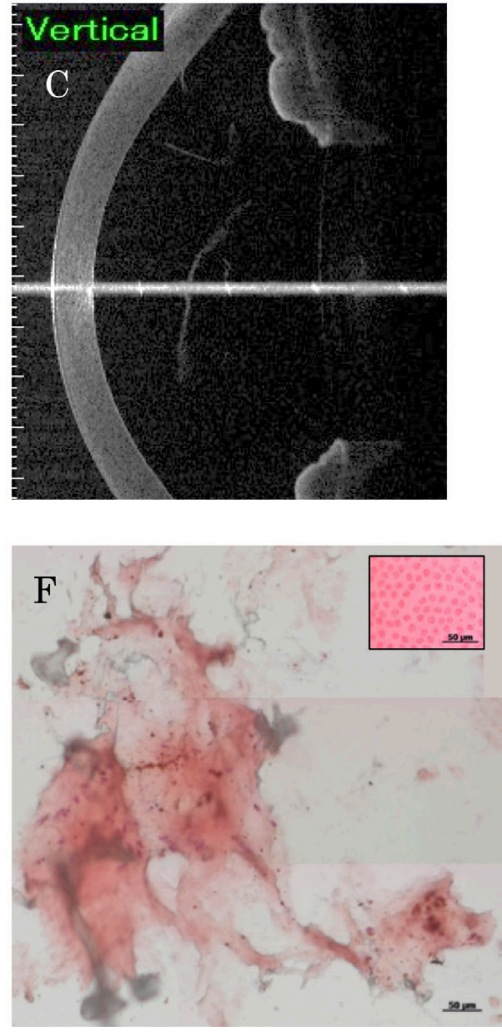

Figure 1 (A) Slit lamp photography of case 1. Note that transparent membranous materials were located in the anterior chamber. (B) Slit lamp photography with dilated pupil demonstrated no abnormal depositions on the lens surface. The iris was also normal. (C) AS-OCT revealed the presence of the membrane. (D) Another AS-OCT image confirmed that the membrane was attached to the corneal endothelium. (E) Confocal microscopy showed the presence of a round hyporeflective structure in each cell. (F) Histological examination showed the acellular structure of the membrane (Alizarin red S staining). Inset: normal corneal endothelium (positive control). AS-OCT, Anterior segment optical coherence tomography .

\section{Case 2}

A 52-year-old healthy housewife was referred to our hospital because of floating materials in the anterior chamber of the left eye. The BCVA was 20/15 and the IOP was $20 \mathrm{~mm} \mathrm{Hg}$. The patient did not have any history of systemic diseases or traumatic events to her eyes. Slit lamp examination showed a fibrin-like material in the inferior anterior chamber (figure 4A,B). There was no corneal oedema or 'hammered-silver appearance', and the central corneal thickness was $528 \mu \mathrm{m}$. AS-OCT showed that the material was present in the inferior angle (figure 4C). No anterior chamber reaction was noted. The iris and angle showed no abnormalities, and gonioscopy showed no peripheral anterior synechiae. The crystalline lens was clear and there were no abnormal deposits on the surface. Specular microscopy showed reversal of the corneal endothelium in the left eye but not in

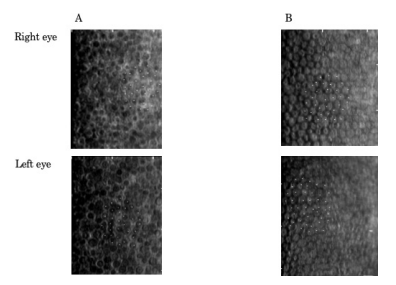

Figure 2 Specular microscopic images of the right eye (upper) and the left eye (lower) of case 1. (A) First examination. Note the reversal of normal light/dark patterns in both eyes. (B) Three months after the first visit, the specular image changed to a normal appearance. The white dots in each picture were generated by the automated cell counting software. the right eye (figure 4D). The endothelial cell density was 2899/ $\mathrm{mm}^{2}$ in the right eye and $2368 / \mathrm{mm}^{2}$ in the left eye. Confocal microscopy findings in the corneal endothelium were similar to those in case 1 . With the patient's consent, tissue extraction was performed 3 weeks after initial presentation, with the results of the analysis thereof then used to make the diagnosis. Because the material was fragile, extraction was performed via paracentesis with gentle anterior chamber irrigation using BSS-plus (Alcon, Geneva, Switzerland). Histological examination showed acellular membranous materials (figure 4E).

Over 26 months of close follow-up, the anterior chamber membranous materials were usually present, sometimes in the inferior chamber but occasionally attached to the nasal region on the endothelial side. Specular microscopy showed reversed images with periodic improvement in the image. No notable changes were seen in the iris, angle or cornea. The IOPs were 20-25 mm Hg without a glaucomatous change in the optic nerve.

\section{DIFFERENTIAL DIAGNOSIS}

Our cases showed some similarities with iridocorneal endothelial (ICE) syndrome in specular images of the corneal endothelium. However, other findings such as presence of acellular materials in the anterior chamber, as well as absence of alterations in the iris and chamber angle, did not match the ICE sysndrome.

\section{TREATMENT}

Topical corticosteroids were given to both cases without any changes. 


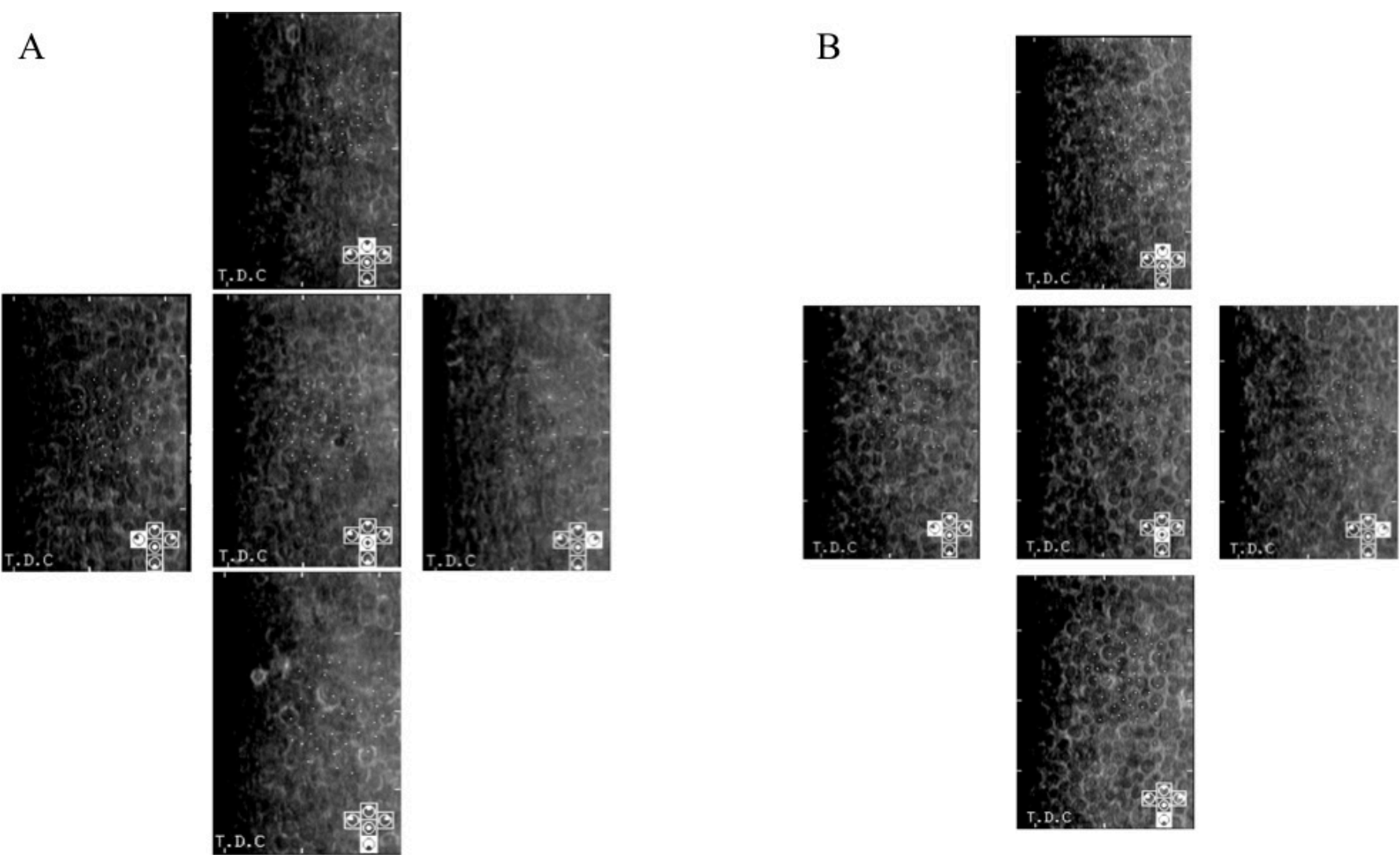

Figure 3 Specular microscopic images of case 1. (A) Right eye and (B) left eye. Endothelial cells were observed in both eyes without notable regional differences.

\section{OUTCOME AND FOLLOW-UP}

During the follow-ups (3 years in case 1 and 2 years in case 2), the materials gradually changed shape and location. There were no changes in vision, the iris or the chamber angle.

\section{DISCUSSION}

We describe two unusual cases characterised by (1) continuous presence of membrane-like materials in the anterior chamber; (2) reversal of the dark/light image using specular microscopy, which occasionally changed to a normal appearance; (3) normal endothelial counts without corneal oedema; (4) no apparent
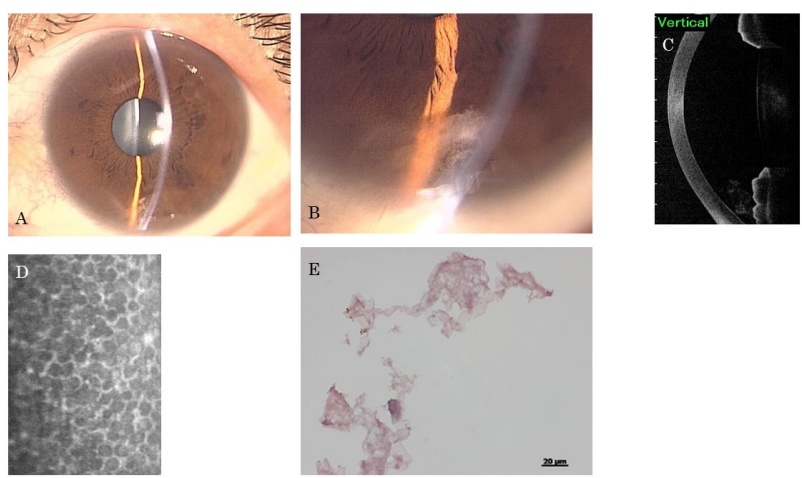

Figure $4 \quad(A, B)$ Slit lamp photography of case 2. Fibrinous material was located in the inferior part of the anterior chamber. (C) AS-OCT showed that the material was located at the inferior angle. (D) Specular microscopy showed an abnormal endothelial image in the left eye but not in the right eye. (E) Histological examination showed the acellular structure of the material (Alizarin red S staining). inflammation in the anterior chamber; and (5) no abnormalities in the iris, pupil or angle.

Despite the aforementioned similarities, these two cases seemed to have some differences. While the materials in the anterior chambers appeared transparent and membranous in case 1, they appeared fibrinous in case 2. Changes in the endothelial image were seen in bilateral eyes in case 1 but unilaterally in Case 2. While there was an occasional episode of mild ciliary injection without cellular reaction in the anterior chamber in case 1 , no such event was noted in case 2 . Case 2 showed mild elevation of the IOP without changes in the optic disc or anterior chamber angle.

Reversed images on specular microscopy have been reported in ICE syndrome, especially in Chandler's syndrome. ${ }^{12}$ This appearance was explained as endothelial cell nuclei and blebs of the apical cell membrane. ${ }^{3}$ These cells are regarded as pathognomonic for ICE syndrome and so have been termed ICE cells. ${ }^{4}$ However, several findings in our cases did not match the characteristics of ICE syndrome. First, the specular microscopic changes seemed to be reversible, returning almost to normal (without changes in symptoms or other signs) in our cases. The changes seemed to occur in a diffuse manner without remarkable regional differences (figure 3). Notably, morphological alterations occurred simultaneously in both eyes. Although dual populations of ICE cells and normal endothelium may be seen in the early stage of ICE syndrome, ${ }^{25}$ reversibility of the image has not been reported. Second, case 1 exhibited bilateral changes in the specular images. Although bilateral involvement in the corneal endothelium has been reported, ICE syndrome is basically a unilateral disease. ${ }^{67}$ Third, the production of acellular materials has not been reported in ICE syndrome. Fourth, there 
were no abnormal findings by slit lamp examination, such as a hammered-silver appearance. Finally, the cases did not show any progression after being followed up for several years.

Another clinical entity, which must be distinguished, is uveitis-membranous tissue production may be a result of inflammation. Indeed, there were episodes of occasional ciliary injection in case 1. It is conceivable that chronic intermittent inflammation could have been responsible for the production of materials in the anterior chamber. However, clinical findings did not suggest that uveitis led to the production of these materials. We did not observe any signs of anterior chamber inflammation, and the patient did not respond to steroid administration. Notably, our cases did not exhibit uveitis with specular microscopic changes. The other possible disorders that may produce materials in the anterior chamber include exfoliation/pseudoexfoliation syndrome. However, we did not find any deposits on the crystalline lens, and both patients did not have history of long-term heat exposure such as seen in glassblowers. Also, both the iris and lens demonstrated no abnormal findings that may be associated with iris chaffing over the lens. 'Intracellular shadowing' of the corneal endothelium has been shown by specular microscopy in hard contact lens wearers. However, this was not seen in endothelial images, and neither case had a history of wearing hard contact lenses. ${ }^{8}$

In 1987, Stock et $a l^{9}$ reported a case of 'desquamating endotheliopathy' with unilateral corneal oedema seen in a 34-year-old man. Histopathological examination showed focal necrosis of corneal endothelial cells with desquamation of cells in the anterior chamber. The authors speculated that the case represented an incipient form of ICE syndrome. Although there are some similarities between our cases and this report, we did not observe endothelial damage, and the materials in the anterior chamber did not contain cells. We presume that the production

\section{Learning points}

- We describe two cases in which acellular materials were continuously produced in the anterior chamber.

- Serial ophthalmic examinations and histopathological findings suggest that the production of the material was associated with metabolic alterations of the corneal endothelium.

- These cases may represent an incipient form of iridocorneal endothelial syndrome. of membranous/fibrinous material and corneal changes in endothelial images have pathological relevance. The corneal endothelium in our cases may have been metabolically activated to continuously produce acellular materials in the anterior chamber, although normal pump function was maintained. It is also conceivable that our cases later developed iris and/or angle abnormalities, as seen in ICE syndrome. If so, membranous material production and reversible endothelial specular images might be considered early manifestations of ICE syndrome.

Acknowledgements The authors thank Drs Takefumi Yamaguchi and Takashi Kojima for their contribution to the analysis of the data and for generating this article.

Contributors Acquisition, analysis or interpretation of data; final approval of the version published; agreement to be accountable for all aspects of the work in ensuring that questions related to the accuracy or integrity of any part of the work are appropriately investigated and resolved: all authors. Drafting the work or revising it critically for important intellectual content: JS and $\mathrm{KH}$.

Funding The authors have not declared a specific grant for this research from any funding agency in the public, commercial or not-for-profit sectors.

Competing interests None declared.

Patient consent for publication Obtained.

Provenance and peer review Not commissioned; externally peer reviewed.

Open access This is an open access article distributed in accordance with the Creative Commons Attribution Non Commercial (CC BY-NC 4.0) license, which permits others to distribute, remix, adapt, build upon this work non-commercially, and license their derivative works on different terms, provided the original work is properly cited and the use is non-commercial. See: http://creativecommons.org/ licenses/by-nc/4.0/.

\section{REFERENCES}

1 Hirst LW, Quigley HA, Stark WJ, et al. Specular microscopy of iridocorneal endothelia syndrome. Am J Ophthalmol 1980;89:11-21.

2 Laganowski HC, Sherrard ES, Muir MG, et al. Distinguishing features of the iridocorneal endothelial syndrome and posterior polymorphous dystrophy: value of endothelial specular microscopy. Br J Ophthalmol 1991;75:212-6.

3 Alvarado JA, Murphy CG, Maglio M, et al. Pathogenesis of Chandler's syndrome, essential iris atrophy and the Cogan-Reese syndrome. I. alterations of the corneal endothelium. Invest Ophthalmo/ Vis Sci 1986;27:853-72.

4 Levy SG, McCartney AC, Baghai MH, et al. Pathology of the iridocorneal-endothelial syndrome. The ICE-cell. Invest Ophthalmol Vis Sci 1995;36:2592-601.

5 Levy SG, Kirkness CM, Moss J, et al. On the pathology of the iridocorneal-endothelial syndrome: the ultrastructural appearances of 'subtotal-ice'. Eye 1995;9:318-23.

6 Hemady RK, Patel A, Blum S, et al. Bilateral iridocorneal endothelial syndrome: case report and review of the literature. Cornea 1994;13:368-72.

7 Kaiser-Kupfer M, Kuwabara T, Kupfer C. Progressive bilateral essential iris atrophy. Am J Ophthalmol 1977:83:340-6.

8 Hirst LW, Auer C, Cohn J, et al. Specular microscopy of hard contact lens wearers. Ophthalmology 1984;91:1147-53

9 Stock EL, Roth SI, Morimoto D. Desquamating endotheliopathy. An incipient iridocorneal endothelial syndrome? Arch Ophthalmol 1987;105:1378-81.

Copyright 2020 BMJ Publishing Group. All rights reserved. For permission to reuse any of this content visit https://www.bmi.com/company/products-services/rights-and-licensing/permissions/

BMJ Case Report Fellows may re-use this article for personal use and teaching without any further permission.

Become a Fellow of BMJ Case Reports today and you can:

- Submit as many cases as you like

Enjoy fast sympathetic peer review and rapid publication of accepted articles

- Access all the published articles

- Re-use any of the published material for personal use and teaching without further permission

Customer Service

If you have any further queries about your subscription, please contact our customer services team on +44 (0) 2071111105 or via email at support@bmj.com.

Visit casereports.bmj.com for more articles like this and to become a Fellow 